\title{
Sensitivity study of an upper ocean model in a coastal bay
}

\author{
J. Gan ${ }^{\mathrm{a}, *}$, R.G. Ingram ${ }^{\mathrm{a}}$, R.J. Greatbatch ${ }^{\mathrm{b}}$ \\ a Dep. of Atmospheric and Oceanic Sciences, McGill University, Montreal, Quebec, Canada, H3A, 2Ko \\ ${ }^{\mathrm{b}}$ Dep. of Physics, Memorial University of Newfoundland, St. John's, Newfoundland, Canada, A1B $3 X 7$ \\ Received 11 July 1994; accepted 10 January 1995
}

\begin{abstract}
An upper layer ocean model, with primitive equation dynamics and embedded with a mixed layer model at the top, is developed. Entrainment and detrainment in the mixed layer are determined from wind and buoyancy turbulent kinetic energy, as well as the effect of shear instability at the base of the mixed layer. The model parameterised the processes of convection and deep ocean diffusion, as well as mass entrainment at a subsurface layer due to strong upwelling. It was applied to the Baie des Chaleurs (Gulf of St. Lawrence, Canada). The model was forced by observed winds, atmospheric heat fluxes, river runoff and a remote coastal jet. The simulations in the main run reproduced well the observational fields in both time and space. Sensitivity runs are conducted to study the effects of external forcing, important physical processes and the internal physical parameterisation on the model results and to compare these with the main run.
\end{abstract}

\section{Introduction}

The upper ocean supplies most of the energy for circulation and turbulence within the ocean interior. Upper ocean models incorporating both dynamical and thermodynamic processes and resolving mixed layer (ML) physics, have been successfully applied in the tropical region (e.g., Schopf and Cane, 1983; McCreary and Kundu, 1988), as well as in large scale climate studies (Cherniawsky et al., 1990; Yuen et al., 1992). There are few similar studies in the coastal region, where relatively small spatial and time scales occur. Coastal regions, which account for about $25 \%$ of global biological production, have their primary production concentrated in the top of

\footnotetext{
${ }^{*}$ Corresponding author.
}

the water column. With less numerical cost and resolution of physical processes in the ML, upper ocean modelling can help determining not only physical processes, but also major biological processes, by coupling with a biological model. The characteristics of the layer model facilitates tracing water masses in the coastal region, where both coastal discharges and open ocean inflows come together.

The ocean responses to changes of the external dynamical and thermodynamic forcing such as wind stress, atmospheric heat fluxes, fresh water input and remote forcing. Sensitivity experiments of the external forcing can provide further understanding of both the physical mechanisms and the model itself.

Inclusion of the appropriate ML physics into the ocean model is important for interpreting physical processes, especially those near the sur- 


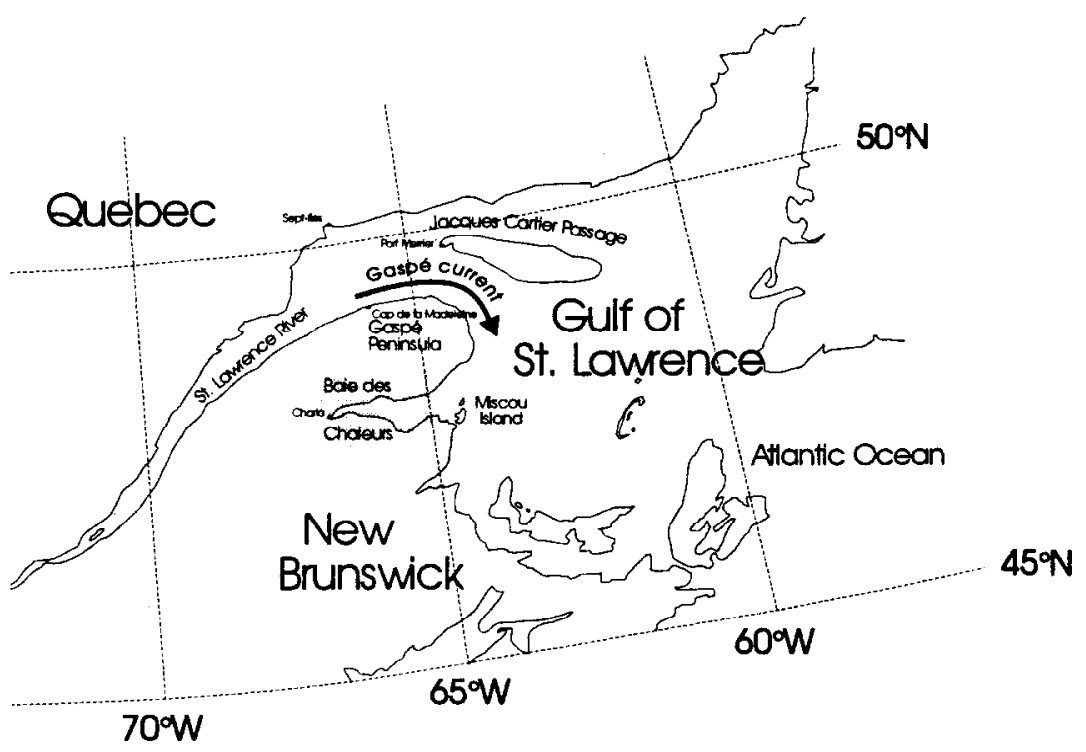

Fig. 1. Geographic location of Baie des Chaleurs.

face. Following the pioneering work of Kraus and Turner (1967), the bulk form of ML models has been modified and developed in many studies (e.g., Denman, 1973; Garwood, 1977; Niiler and Kraus, 1977, etc.). However, uncertainty about the parameterised coefficients still remains. Previous applications of the ML model were mainly conducted in the open ocean where observations are few and coefficients difficult to verify. In the near shore region, with more observations of both the hydrographic and atmospheric fields, it is easier to examine the ML model coefficients.

Baie des Chaleurs (BdC), is a semi-enclosed basin (Fig. 1), located on the west coast of the

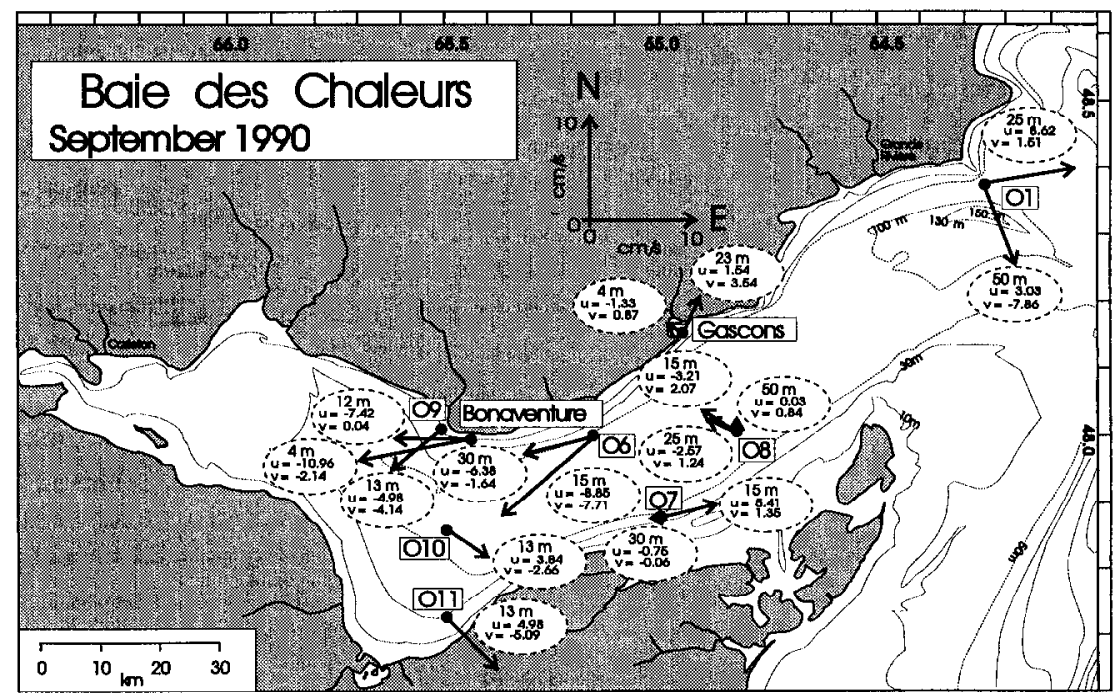

Fig. 2. Bathymetry, current meter moorings and mean observed circulation in BdC in September, 1990. The station numbers are in the rectangular boxes. The $u$ and $v$ in the ovals are E-W and N-S components of velocity, respectively. The depth of current meters is shown in the ovals. (adapted from Gan et al., 1995a) 
Gulf of St.Lawrence, Canada. At the northwest of the Gulf, wind-induced upwelling plus buoyancy output from St. Lawrence river runoff, generates a strong surface coastal jet, the Gaspé Current (GC). It has a maximum speed of 100 $\mathrm{cm} / \mathrm{s}$ in June. Part of the GC moved along Gaspé peninsula and intruded into the BdC (El-Sabh, 1976). The dynamics and thermodynamics of BdC are influenced by the prevailing westerlies, GC intrusion, river discharge and atmospheric heat fluxes (Gan et al., 1995a). Observations showed that the mean circulation in the bay was cyclonic (Fig. 2), as the westward GC intrusion exceeds the influence of the eastward prevailing wind.

The objective of this paper is to study the sensitivity of the model to both external forcing and changes of internal physical parameters. Following a description of the model formulation and its numerical implementation in Section 2, the mean dynamical and thermodynamical results in BdC from the main run are given in Section 3. Numerical experiments for different external forcing as well as certain physical processes are presented in Section 4. The parameter study is conducted in Section 5. A summary of results and some concluding remarks are given in Section 6 .

\section{Model formulations and its numerical imple- mentations}

The model consists of two active layers and a deep resting lower layer. The equations for momentum, continuity, temperature and salinity for the upper and lower layer are (Gan et al., 1995a):

$$
\begin{aligned}
& \left(h_{1} V_{1}\right)_{t}+\nabla \cdot\left(h_{1} V_{1} V_{1}\right)+f K \times h_{1} V_{1} \\
& =\frac{\tau_{0}}{\rho_{0}}-h_{1} \nabla P_{1}+W_{e}\left[H\left(W_{e}\right) V_{2}+H\left(-W_{e}\right) V_{I}\right] \\
& \quad+K_{u} \nabla \cdot\left(h_{1} \nabla V_{1}\right) \\
& \left(h_{1}\right)_{t}+\nabla \cdot\left(h_{1} V_{1}\right)=W_{e} \\
& \left(h_{1} T_{1}\right)_{t}+\nabla \cdot\left(h_{1} V_{1} T_{1}\right) \\
& =\frac{Q_{1}}{\rho_{0} C_{p}}+W_{e}\left[H\left(W_{e}\right) T_{e}+H\left(-W_{e}\right) T_{1}\right] \\
& \quad+K_{m} \nabla \cdot\left(h_{1} \nabla T_{1}\right)+C_{T 1}
\end{aligned}
$$

$$
\begin{aligned}
& \left(h_{1} S_{1}\right)_{t}+\nabla \cdot\left(h_{1} V_{1} S_{1}\right) \\
& =W_{e}\left[H\left(W_{e}\right) S_{e}+H\left(-W_{e}\right) S_{1}\right] \\
& \quad+K_{m} \nabla \cdot\left(h_{1} \nabla S_{1}\right)+C_{S 1} \\
& \left(h_{2} V_{2}\right)_{t}+\nabla \cdot\left(h_{2} V_{2} V_{2}\right)+f K \times h_{2} V_{2} \\
& =-h_{2} \nabla P_{2}-W_{e}\left[H\left(W_{e}\right) V_{2}+H\left(-W_{e}\right) V_{1}\right] \\
& \quad+W_{r} V_{r}+K_{u} \nabla \cdot\left(h_{2} \nabla V_{2}\right) \\
& \left(h_{2}\right)_{t}+\nabla \cdot\left(h_{2} V_{2}\right)=-W_{e}+W_{r} \\
& \left(h_{2} T_{2}\right)_{t}+\nabla \cdot\left(h_{2} V_{2} T_{2}\right) \\
& \quad Q_{2}-W_{e}\left[H\left(W_{e}\right) T_{e}+H\left(-W_{e}\right) T_{1}\right] \\
& R_{0} C_{p} \\
& \quad+W_{r} T_{r}+K_{m} \nabla \cdot\left(h_{2} \nabla T_{2}\right)+C_{T 2}+N_{T} \\
& \left(h_{2} S_{2}\right)_{t}+\nabla \cdot\left(h_{2} V_{2} S_{2}\right) \\
& =-W_{e}\left[H\left(W_{e}\right) S_{e}+H\left(-W_{e}\right) S_{1}\right] \\
& \quad+W_{r} S_{r}+K_{m} \nabla \cdot\left(h_{2} \nabla S_{2}\right)+C_{S 2}+N_{S}
\end{aligned}
$$

$H$ is the Heaviside step function, $\tau_{0}$ is wind stress and $C_{p}$ is specific heat of water $\left(=4025 \mathrm{Jkg}^{-1}\right)$. Horizontal pressure gradients at the ML and subsurface layer are

$\nabla P_{1}=\nabla\left(g_{1}^{\prime} h_{1}+g_{2}^{\prime} h\right)-h_{1} \nabla\left(g_{1}^{\prime} / 2\right)$

$\nabla P_{2}=\nabla\left(g_{2}^{\prime} h_{2} / 2\right)+g_{2}^{\prime} \nabla\left(h_{1}+h_{2} / 2\right)$

where $g_{1}^{\prime}$ and $g_{2}^{\prime}$ are defined as: $g_{1}^{\prime}=g\left(\rho_{3}\right.$ $\left.\rho_{1}\right) / \rho_{0} ; g_{2}^{\prime}=g\left(\rho_{3}-\rho_{2}\right) / \rho_{0} ; \rho_{3}$ is the density of the deep ocean or lowest layer, which remains spatially constant. $g$ is gravity and $\rho_{0}$ is a reference density. $K_{u}$ and $K_{m}$ are horizontal eddy viscosity and diffusivity coefficients $\left(K_{u}=40\right.$ $\left.\mathrm{m}^{2} / \mathrm{s}, K_{m}=30 \mathrm{~m}^{2} / \mathrm{s}\right) . T_{e}$ and $S_{e}$ are the temperature and salinity at the interface between the ML and the layer below, which are obtained by assuming linear stratification below the ML. $T_{1.2}$ and $S_{1,2}$ are defined at the mid-depth of the layer. Therefore, we have $T_{e}=2 T_{2}-T_{3}$ and $S_{e}=$ $2 S_{2}-S_{3}$ when $W_{\mathrm{e}}>0 . T_{3}$ and $S_{3}$ are the temperature and salinity in the deep ocean. When $W_{\mathrm{e}}<$ $0,\left(T_{\mathrm{e}} S_{\mathrm{e}}\right)=\left(T_{1}, S_{1}\right)$. The surface and interfacial temperature fluxes $\mathbf{Q}_{1,2}$ are given by

$$
\begin{aligned}
& Q_{1}=Q_{o}(1-a)-L_{a}-H_{a}-L E_{a}-I(0) e^{-h_{1} / h_{s}} \\
& Q_{2}=I(0) e^{-h_{1} / h_{s}}
\end{aligned}
$$


where $\mathbf{Q}_{o}$ is the measured incoming short wave radiation at the surface, a $(=0.1)$ is the albedo for sea surface. $I(0)$ is the penetrating short wave radiation where $I(0)=C_{r} \mathbf{Q}_{o} . C_{r}$ and $h_{s}$ are listed in Table $1 . L_{a}$ is long wave radiation (Budyko, 1974),

$$
\begin{aligned}
L_{a}= & \epsilon \sigma T_{1}^{4}\left(0.39-0.05 e_{a}^{1 / 2}\left(1-0.71 C^{2}\right)\right) \\
& +4 \epsilon \sigma T_{a}^{3}\left(T_{1}-T_{a}\right)
\end{aligned}
$$

where $\epsilon$ is the emissivity of the ocean $(0.97), \sigma$ is the Stefan-Boltzmann constant, $e_{a}(\mathrm{mb})$ is the atmospheric vapor pressure, which can be defined as $e_{a}=\mathbf{r} e_{\text {sat }}\left(T_{a}\right)$. $\mathbf{r}$ is the relative humidity and $\rho_{a}$ is air density $\left(1.3 \mathrm{~kg} / \mathrm{m}_{3}\right)$. $C$ is the cloud amount $(0-1.0)$. $\mathrm{L}$ is the latent heat of vaporization $\left(2.5 \times 10^{6} \mathrm{Jkg}^{-1}\right)$. The sensible and latent heat are calculated by the standard bulk turbulent formula,

$H_{a}=\rho_{a} C_{p, a i r} C_{a}|W|\left(T_{1}-T_{a}\right)$

$E_{a}=\rho_{a} C_{L}|W|\left(e_{s a t}\left(T_{1}\right)-r e_{s a t}\left(T_{a}\right)\right)\left(\frac{0.622}{p_{a}}\right)$

where $C_{p, \text { air }}=1004 \mathrm{Jkg}^{-1} \mathrm{~K}^{-1}$ is the specific heat of air. $C_{\mathrm{a}}\left(=10^{-3}\right)$ and $C_{\mathrm{L}}\left(=10^{-3}\right)$ are the turbulent exchange coefficients. $p_{\mathrm{a}}$ is the sea level pressure, $|\mathrm{W}|$ is the wind magnitude. $e_{\text {sat }}$ is saturation vapor pressure and is computed by the empirical formula given by Bolton (1980),

$e_{\text {sat }}(T)=6.112 e^{\frac{17.67 T}{T+243.5}}$
The model includes instantaneous convection between the ML and subsurface layer $\left(C_{T 1}, C_{S 1}\right)$ and deep convection between the subsurface layer and the deep ocean $\left(C_{T 2}, C_{S 2}\right)$. The upper convection employed a depth weighted scheme while the deeper one was similar to Yuen et al., (1992). $N_{T, S}$ are the heat and salt diffusion between the second layer and the deep ocean. $N_{T}=H N\left(T_{3}-\right.$ $\left.T_{2}\right)$ and $N_{s}=H N\left(\mathrm{~S}_{3}-\mathrm{S}_{2}\right)$. The coupling coefficient $H N$ is equal to $5 \times 10^{-7} \mathrm{~m} / \mathrm{s}$.

$W_{e}$ in the model is the entrainment/detrainment rate and is determined from the Niiler and Kraus (1977) type formulation,

$$
\begin{aligned}
& W_{e} g^{\prime} h_{1}-W_{e} R i_{c r i t}\left[\left(u_{2}-u_{1}\right)^{2}+\left(v_{2}-v_{1}\right)^{2}\right] \\
& =2 m_{0} U_{*}^{3} e^{-\frac{h_{1}}{h_{d}}}-h_{1} m_{1} B_{0}-\frac{g \alpha h_{1} D\left(h_{1}\right) I(0)}{C_{p} \rho_{0}}
\end{aligned}
$$

where $g^{\prime}=g\left(\rho_{2}-\rho_{1}\right) / \rho_{0}, R i_{\text {crit }}$ is the critical Richardson number between the $\mathrm{ML}$ and the subsurface layer below and is set to 0.25 (Oberhuber, 1992). $U_{*}=\left(\tau / \rho_{1}\right)^{1 / 2}$ is the friction velocity. The function $D\left(h_{1}\right)$ is given by $D\left(h_{1}\right)=1$ $-2 h_{\mathrm{s}} / h_{1}+e^{-h_{1} / h_{\mathrm{s}}}\left(1+2 h_{\mathrm{s}} / h_{1}\right)$ (Kim, 1976). The buoyancy flux at the base of the ML due to penetrating solar radiation. $B_{0}$ can be expressed as

$$
B_{0}=\frac{g\left(\alpha Q_{1}+\beta Q_{R}\right)}{\rho_{0} C_{p}}
$$

Table 1

Model Parameters

\begin{tabular}{lll}
\hline Parameters & Values & Description \\
\hline$\Delta t$ & $10 \mathrm{~min}$ & time step \\
$\Delta X / Y$ & $4 / 2 \mathrm{~km}$ & grid space \\
$K_{u}$ & $40 \mathrm{~m}^{2} / \mathrm{s}$ & horizontal viscosity \\
$K_{m}$ & $30 \mathrm{~m}^{2} / \mathrm{s}$ & horizontal diffusivity \\
$C_{r}$ & $40 \%$ & \% of penetrating short wave radiation \\
$h_{s}$ & $15 \mathrm{~m}$ & attenuation depth of short wave radiation \\
$h_{d}$ & $15 \mathrm{~m}$ & penetration depth of wind-driven turbulence \\
$m_{0}$ & $1.2 \mathrm{~m}$ & wind mixing efficiency \\
$m_{1}$ & $0.83 / 1$ & convective mixing \\
$R i_{c r i t .}$ & 0.25 & critical Richardson number \\
$H N$ & $5 \times 10^{-7} \mathrm{~m} / \mathrm{s}$ & vertical eddy diffusion \\
$T_{e}\left(S_{e}\right)$ & $2 T_{2}\left(S_{2}\right)-T_{1}\left(S_{1}\right)^{\circ} \mathrm{C}(0 / 00)$ & interfacial temperature \\
\hline
\end{tabular}


where $m_{0}$ is a mixing efficiency coefficient associated with wind-driven turbulence and $m_{1}$ is a coefficient associated with frictional energy dissipation of the convective mixing. $\alpha$ and $\beta$ are the heat and salt expansion coefficients, $\alpha=$ $-\left(1 / \rho_{0}\right)(\partial \rho / \partial T), \beta=\left(1 / \rho_{0}\right)(\partial \rho / \partial S)$ and are determined from the equation of state $\rho=\rho(S, T$, $Z)$. The penetration depth scale $\left(h_{d}\right)$ results from wind-driven turbulent dissipation and is taken as $15 \mathrm{~m}$. We take $m_{0}$ equal to 1.2 and $m_{1}=0.83$, if $B_{0}<0$ and $m_{1}=1$ if $B_{0}>0 . Q_{R}$ is equivalent heat flux due to the freshwater flux mainly from precipitation minus evaporation, which was neglected in this study.

$W_{\mathrm{r}}$ in the equations is defined as the residual entrainment rate at the bottom of the second layer (Cherniawsky et al., 1990; Yuen et al., 1992). It equals zero except when the second layer is shallower than the prescribed depth $\left(H_{e}=20 \mathrm{~m}\right.$ in the model). The smoothing function of McCreary and Kundu (1988),

The internal Rossby radius in $\mathrm{BdC}$ is $8 \mathrm{~km}$. An eddy permitting grid size of $\Delta X \times \Delta Y=4 \mathrm{~km} \times 2$ $\mathrm{km}$ was used. An Arakawa-C staggered grid was adopted. An center difference for time and space was applied with a weak filter (Asselin, 1972) controlling time-splitting instability.

$W_{\mathrm{r}}=\frac{\left(H_{e}-h_{2}\right)^{2}}{t_{e} H_{e}}$

has been used in the model. Non-zero $W_{\mathrm{r}}$ could occur when there is a strong upwelling or the ML is deepening in winter. For any volume of water entrained fromthe deeper ocean into the second layer, the same volume of water is evenly deducted everywhere from the second layer in order to keep the mass (and hence heat and salt) conserved. In the model, $V_{r}=0 .\left(=V_{2}\right)$ if $W_{\mathrm{r}}>0$ $(<0)$ and $\left(T_{\mathrm{r}}, S_{\mathrm{r}}\right)=\left(T_{3}, S_{3}\right)$. A summary of model parameters is presented in Table 1.

A modified Orlanski implicit (Camerlengo and O'Brien, 1980) type radiation scheme was applied to the upper $\left(h_{1}\right)$ and lower $\left(h_{2}\right)$ layer depth at open boundaries. We put a zero-gradient condition for along shore velocity and calculated the component normal to shore the same way as in the main program. The condition with zero gradi- ent in layer depth was applied on the northern boundary in order to suppress spurious Kelvin wave propagation (Greatbatch and Otterson, 1991).

To account for the GC intrusion, the southward velocities, which are determined from the across boundary transports, are imposed on the northern boundary at upper and lower layer, respectively. According to the nature of the GC (Bugden, 1981, Benoit and Fl-Sabh, 1985, Mert7. et al., 1988), transports of $1.3 \times 10^{5} \mathrm{~m}^{3} / \mathrm{s}$ and $1.4 \times 10^{4} \mathrm{~m}^{3} / \mathrm{s}$ were applied within $20 \mathrm{~km}$ of the coast line. The northern open boundary was located at the tip of Gaspé peninsula.

To avoid surface outcropping, the minimum $h_{1}$ was set to $2 \mathrm{~m}$ in the model. The temperature and salinity at the boundaries were solved by using the advection equations:

$$
(S, T)_{t}+\boldsymbol{n} \cdot U_{n} \frac{\partial(S, T)}{\partial \boldsymbol{n}}=0
$$

where $\mathbf{n}$ is an unit normal at the boundaries. When flow is into the model domain, the prescribed boundary information, $T_{1,2}$ and $S_{1,2}$, were taken from the longterm climatological mean of data in Petrie (1990).

In the model, the wind stress was calculated following the formula of Large and Pond (1980) from hourly wind speed obtained from the Atmospheric Environment Service (AES) of Environment Canada. The wind speed in the open bay was calculated from the observed wind speed on land at Charlo (Fig. 1) by using the relation suggested by Hsu (1986),

$\left|U_{\text {sea }}\right|=1.62+1.17\left|\boldsymbol{U}_{\text {land }}\right|$

Heat fluxes were calculated from observed atmospheric data. The time frame of this study is from August to September, 1990, which includes both the warm and the start of the cold season, as well as the transition. Initially, the ocean at rest was spun up from April to July with previously observed mean temperature and salinity in April as initial values. The monthly GC transport from Bugden (courtesy of Bugden) also applied from April to July.

The physical time scales of interest for our study in BdC are in the sub-inertial and longer 
periods. The observed forcing in this paper has been low pass filtered to remove energy with periods less than $36 \mathrm{~h}$.

River runoffs at the western part of the bay were specified in the ML near the grid points of
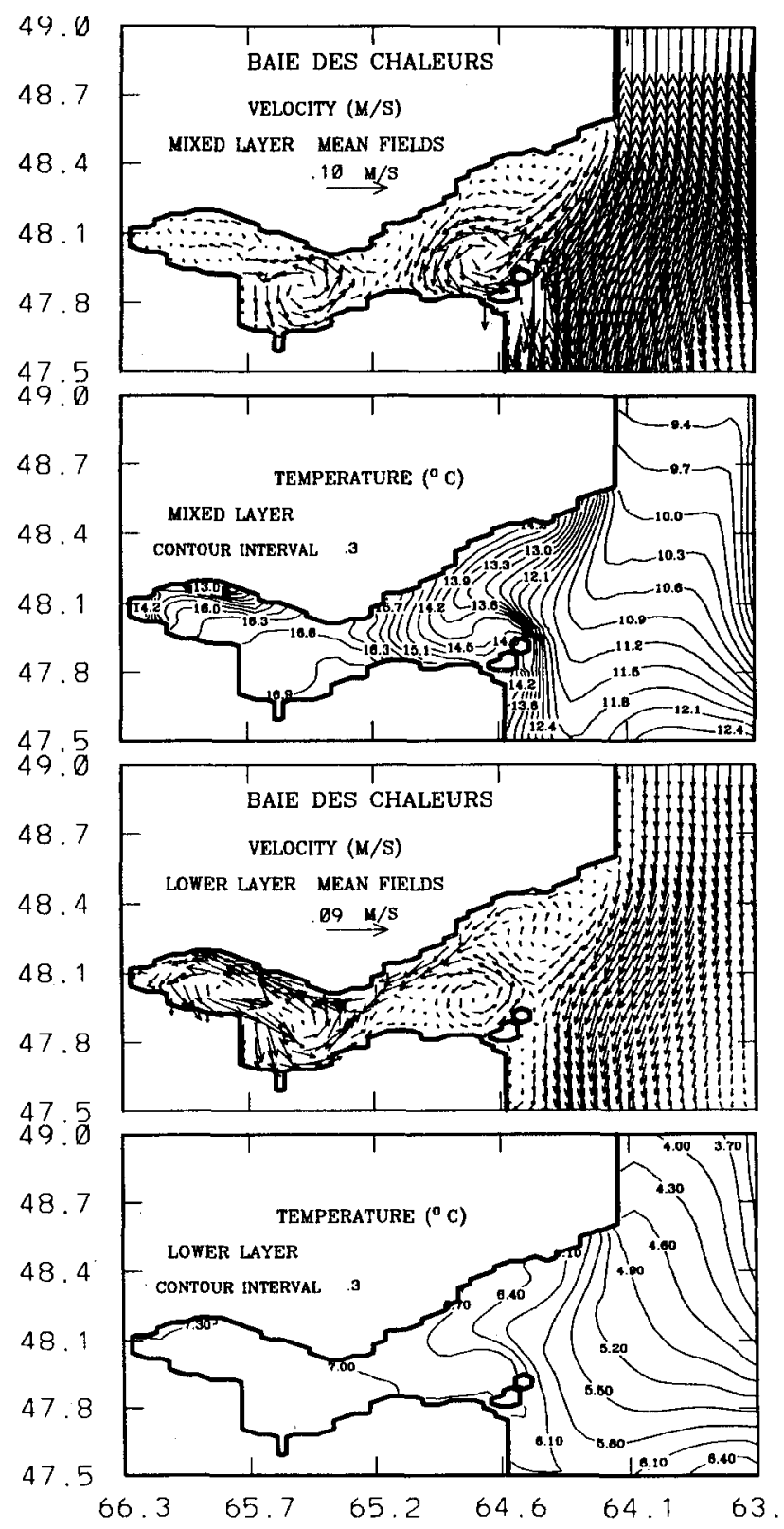

the river exit. Eq. (20) was used to add runoff at these grid points. The velocity at these grid points was calculated by dividing the total discharge by the area of vertical cross section in the runoff zone.
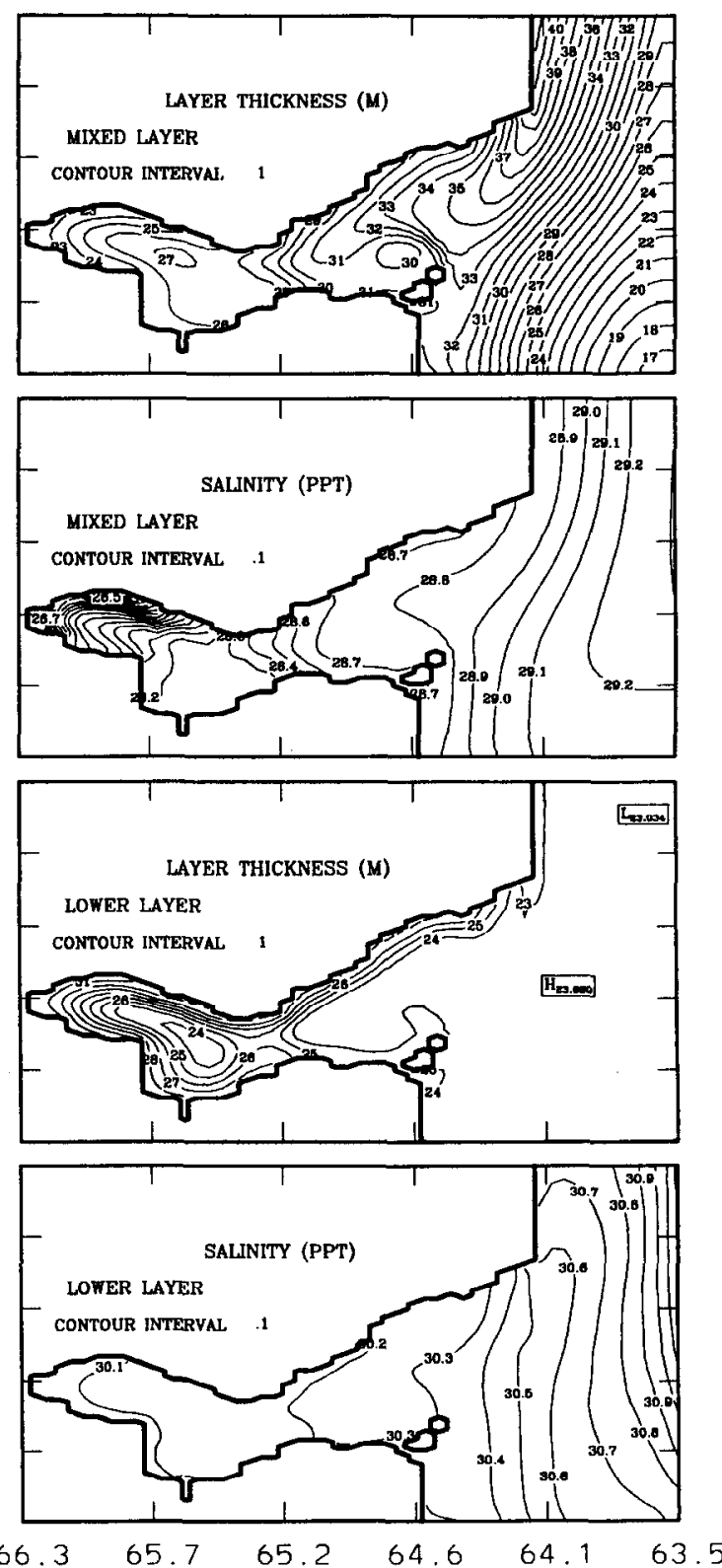

Fig. 3. The two-month mean circulation, temperature, salinity and thickness of ML under observed atmospheric boundary forcing, Gaspe current and river runoff in mixed layer and subsurface layer. The current speed in the figure is truncated at $0.1 \mathrm{~m} / \mathrm{s}$. (adapted from Gan et al., 1995a) 


\section{Main run}

Fig. 3 shows the August and September mean (hereafter referred to as the two-month mean) dynamical and thermodynamic field (Gan et al., 1995a). Although the prevailing wind in BdC was westerly, cyclonic eddies were formed due to the much stronger westward current from the GC intrusion. The mass convergence from the intrusive GC greatly deepened the ML (Gan et al., 1995a) and caused $h_{1}$ to slope down from west to east. The deepest $h_{1}$ was located near the entrance of the bay. The stronger influence of the $\mathrm{GC}$ on the north shore and the weaker eastward current on south shore created a NW-SE orientation of the MLD contours.

Based on the cyclonic circulation pattern in $\mathrm{BdC}$, the resulting thermal fields should be under the influence of colder and more salty Gulf water advected westward by the GC and warm and brackish water advected eastward by the returning flow.

At the lower layer, the GC intrusion also generated cyclonic eddies in the central, western and eastern parts of the bay. Compared to those in the ML, horizontal variation of temperature and salinity gradients were much weaker.

Both the dynamical and thermodynamic numerical results compared reasonably well with the observations (Gan et al., 1995a), in both time and space (Figs. 2 and 4). This, in turn, suggested that the forcing functions and the coefficients

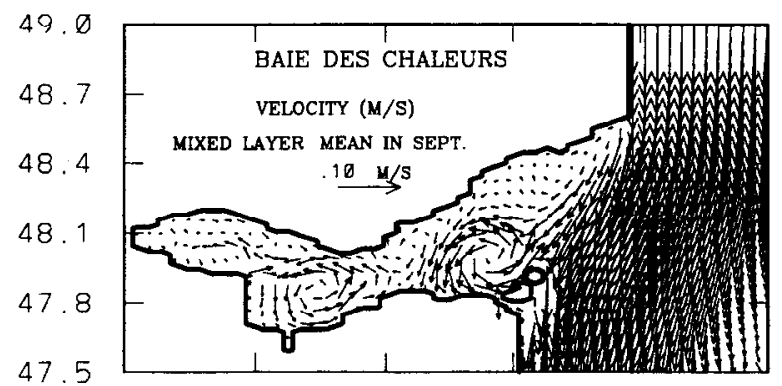

Fig. 4. The mean circulation of ML in September under observed atmospheric boundary forcing, Gaspe current and river runoff. The current speed in the figure is truncated at $0.1 \mathrm{~m} / \mathrm{s}$. (adapted from Gan et al., 1995a)

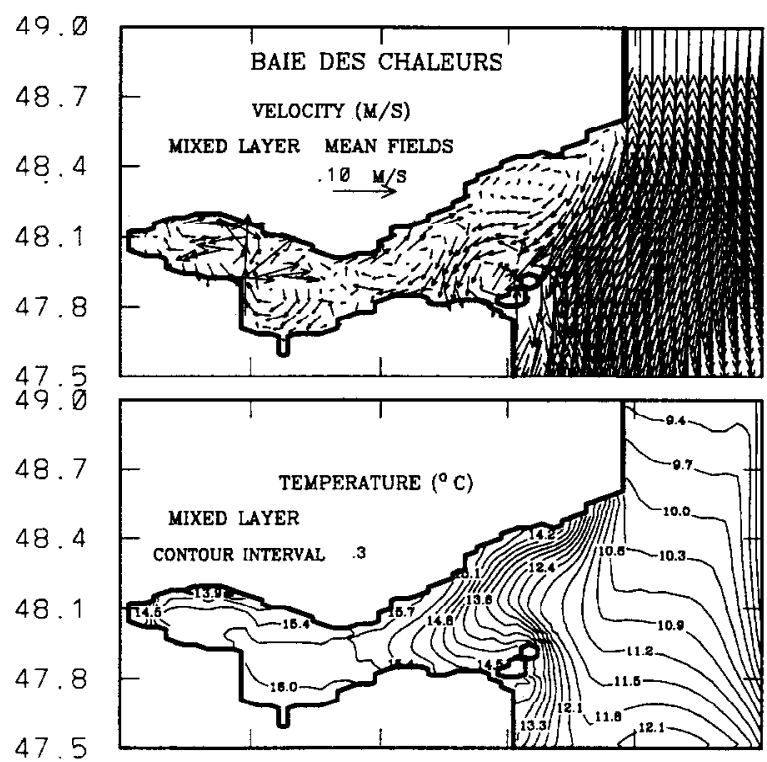

Fig. 5. a, b. Similar to the corresponding maps in Fig. 3, but with wind speed increased $50 \%$.

used in the model were reasonable. In following study, the above results will serve as a standard run. Results from individual sensitivity runs will be compared with this run.

\section{Variation with external forcing}

To examine the variations of the model to the change of external forcing and physical processes in the model, various experiments are performed. In this section, these solutions are compared with those in the standard run.

\subsection{Increase of wind speed}

Fig. 5a shows the circulation with wind speed increased by $50 \%$ after July. As mentioned before, the prevailing westerlies and the GC dominated the dynamical balance in the bay. The intensified westerlies halted the intrusion of the GC mainly in the central part of the bay, which changed the cyclonic circulation in Fig. 3 to anticyclonic.

Higher wind speed has two effects on SST in BdC. Firstly, the intensified eastward wind halted 


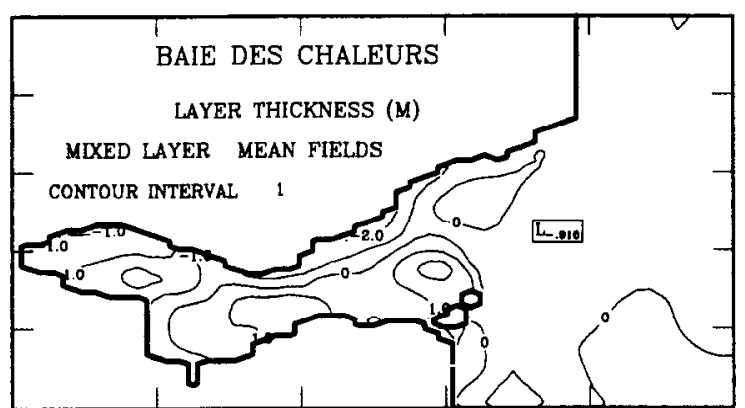

Fig. 6. Difference of two-month mean mixed layer depth between the cases with wind speed increased by $50 \%$ and the main run.

the intrusive colder water and resulted in increased $T_{1}$ (Fig. 5b). Stronger westerly wind also advected colder water at the west end of the bay towards the center and decreased SST there. The NW-SE tilt of temperature and salinity contours in the main run (Fig. 3), thus, was weakened as the wind speed increased. Secondly, a larger wind magnitude can also increase the ocean sensible and latent heat gain (Eqs. 14 and 15). Since our integration period included both warm $\left(T_{a i r}>T_{1}\right)$ and cooling seasons, their net effects were relatively small.

Corresponding to the change of circulation at the ML, the MLD shoaled about 1-2 $\mathrm{m}$ along the north shore (Fig. 6). Fig. 7 shows that the increasing divergence in August shoaled the ML while the divergence enhancement/reduction in September and October almost balanced each other. Stonger wind stress in September and October slightly enhanced entrainment which tended to deepen ML.
Both dynamical and thermodynamic fields in the subsurface layer were not sensitive to the wind speed change (not shown).

\subsection{Cooling of air temperature}

In this experiment, observed air temperatures in August and September were reduced by $5^{\circ} \mathrm{C}$ in order to study the effect of atmospheric thermal fluxes. Compared to values in Fig. 3, SST decrcascd about $2 .-2.5^{\circ} \mathrm{C}$ and $0.3-0.9^{\circ}$ inside the bay and at the entrance, respectively (Fig. 8). Although a stronger $Q_{1}$ loss occurred in the Gulf, the decrease in cold advection made it less efficient in reducing SST there (Fig. 9). Strong atmospheric cooling increased ocean heat losses from longwave radiations, sensible and latent heat (Eqs. 11, 12 and 13). As a result, total heat gain in the $\operatorname{ML}\left(Q_{1}\right.$, in Eq. 11) decreased. Fig. 10 shows the difference of the heat fluxes between the run with colder air temperature and the main run. Higher fluctuations occurred in both sensible and latent heat, which were generally correlated with the wind magnitude. However, the variations in long wave radiation, which wcre not dircetly rclated to wind, were smooth. The results suggest that the main disturbance in temperature resulted mainly from changes of latent and sensible heat flux. The cooler air temperatures deepened MLD by $4-6 \mathrm{~m}$ and $1-2 \mathrm{~m}$ in the bay and Gulf, respectively (Fig. 11). Combined with the change in the thermal field, it rcsultcd in the reduction of coastal convergence (Fig. 12a) and GC intru-

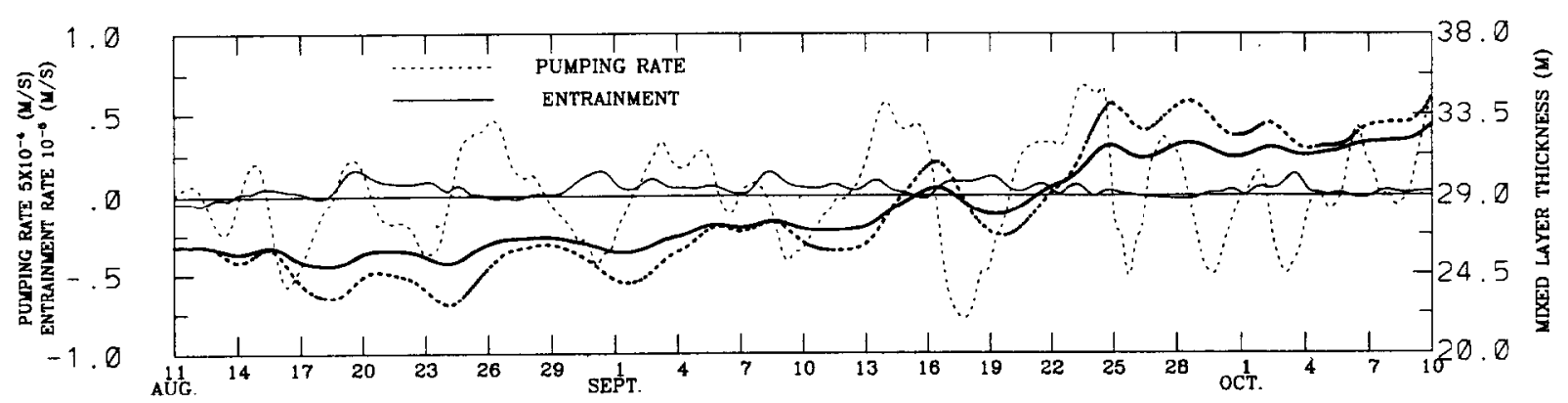

Fig. 7. Difference of bay-averaged pumping rate $\left[-\nabla\left(h_{1} \mathbf{V}_{1}\right)\right]$ and entrainment $\left(W_{e}\right)$ between the cases with wind speed increased by $50 \%$ and the main run. Thick dash and solid lines refer to the bay-averaged mean ML depth in cases with wind speed increased by $50 \%$ and main run, respectively. 


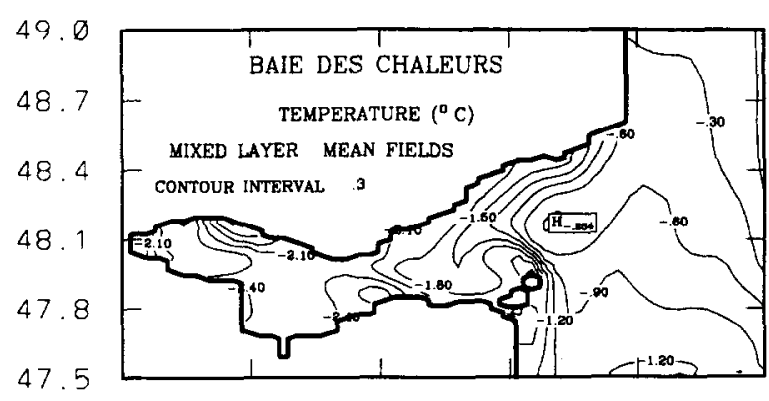

Fig. 8. Difference of the two-month mean SST between cases for air temperature lowered by $5^{\circ} \mathrm{C}$ and the main run.

sion near the entrance (also see Gan et al., 1995b). As mentioned before, the decreased $T_{a}$ dramatically increased ocean heat loss to the atmosphere (Fig. 9). It led to intensify entrainment at the ML (Fig. 12b). Because more $Q_{1}$ was lost to atmosphere in the Gulf (Fig. 9), entrainment was much stronger there than in the bay. However, stronger ML deepening occurred in the bay because it was less influenced by the convergence reduction due to a weakened GC intrusion.

In the subsurface layer, the thickness of the pycnocline and temperatures decreased (not shown).

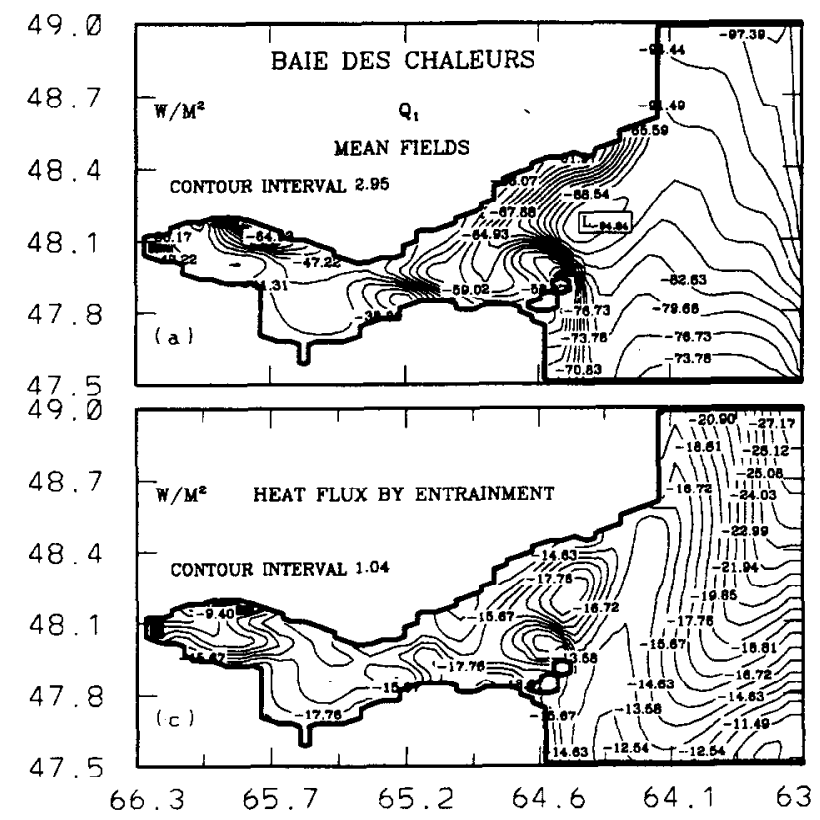

\subsection{Imporlance of momentum flux divergence}

In this experiment, the terms $\nabla \cdot\left(V_{i} h_{i} V_{i}\right)$ in the momentum equations are dropped. One remarkable feature of this run (Fig. 13) was that a stronger $\mathrm{GC}$ intruded into the $\mathrm{BdC}$ along the north shore of the bay without forming the anticyclonic recirculation north of Miscou Island as in the main run (Fig. 3). As mentioned by Batchelor (1967), with large enough Reynolds number $\left(U L / K_{u}\right)$, the flow could lead to the separation, which is defined such that the surface streamlines break away from an object held in a stream and form an eddy. On the other hand, in order to have current separation, negative vorticity must be provided for the anticyclonic recirculation in the lee of the GC. Dengg (1993) showed that the nonlinear term can serve as a transport mechanism for vorticity. As the negative vorticity was created at the no-slip boundary upstream, it was diffused into the whole boundary current and advected downstream. The eastward current to the north of the anticyclonic recirculation, therefore, caused the fluid particles to be forced outward (i.e. separated) near the separation zone. In
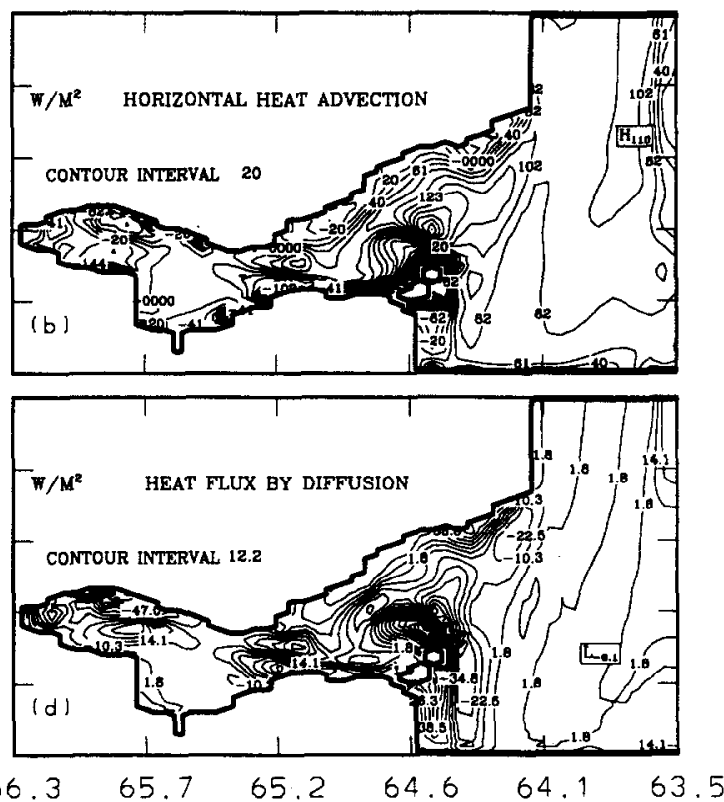

Fig. 9. Difference of the two-month mean of (a) surface heat fluxes, (b) horizontal heat advection, (c) heat flux from entrainment and (d) heat flux from horizontal diffusion between the cases for air temperature lowered by $5^{\circ} \mathrm{C}$ and the main run. 


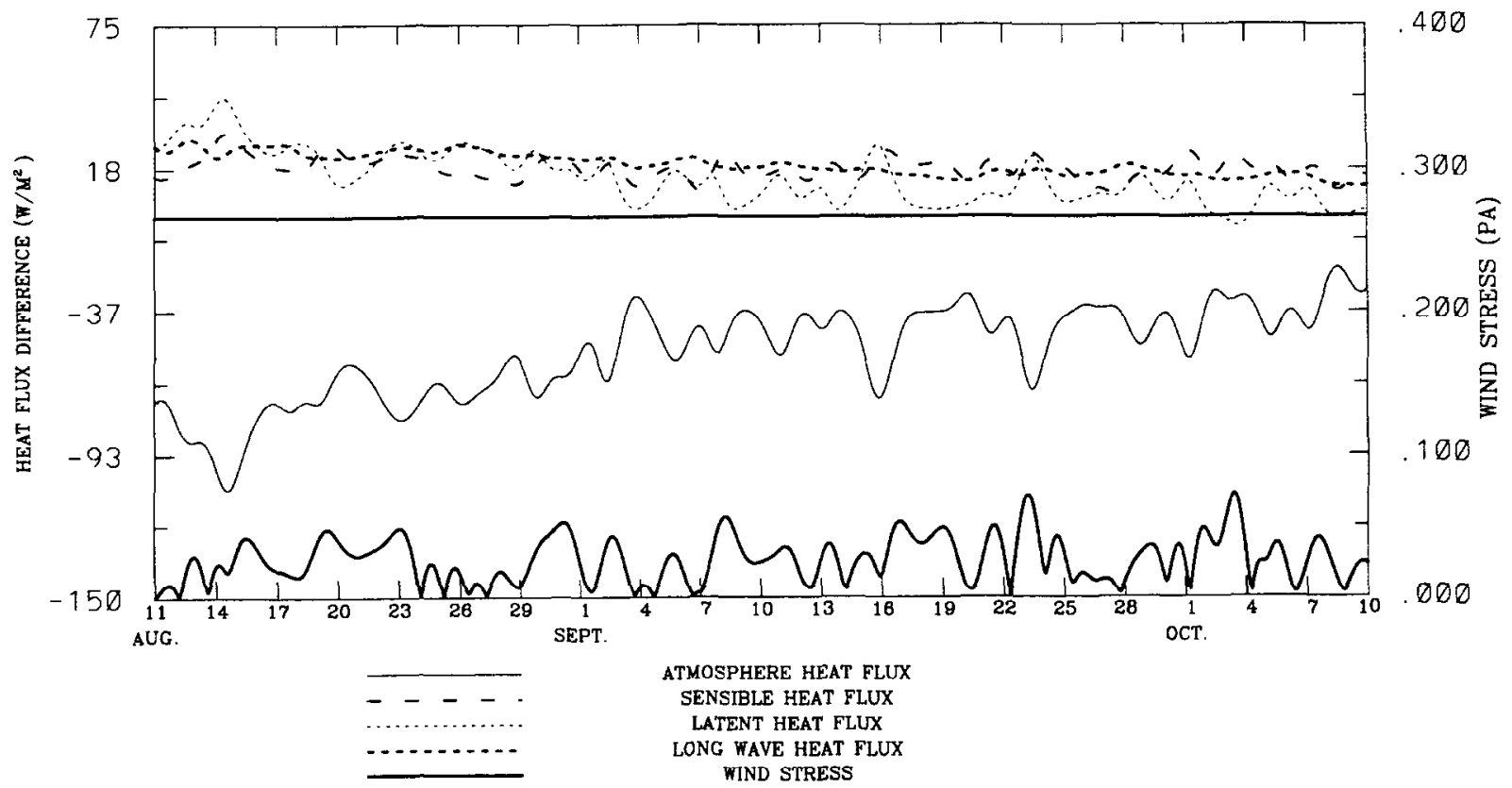

Fig. 10. Difference of time series of atmosphere heat flux, sensible heat flux, latent heat flux and long wave heat flux between the case with air temperature lowered by $5^{\circ} \mathrm{C}$ and the main run.

fact, changing the current pattern downstream, when the nonlinear terms in the momentum equations was neglected, leads to a change in the local balance of pressure gradient, Coriolis and centrifugal forces, which is crucial to the separation processes (Cherniawsky and LeBlond, 1986). Detailed mechanism of the GC separation are discussed by Gan et al. (1995b). The effect of nonlinearity on separation also suggests that as the GC intensifies, the possibility of its scparation

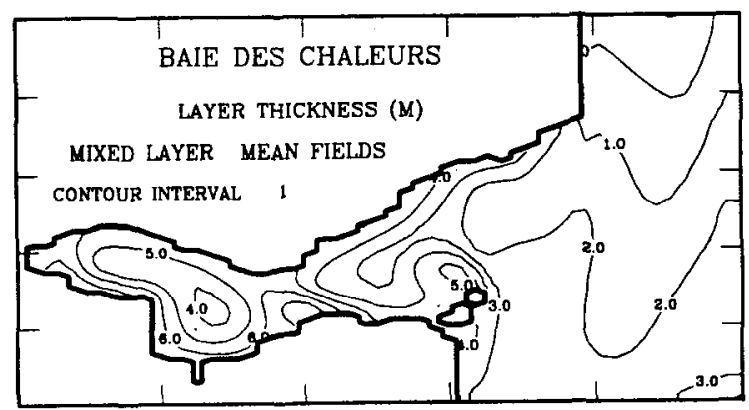

Fig. 11. Difference of two-month mean mixed layer depth between the cases for air temperature decreased by $5^{\circ} \mathrm{C}$ and the main run. increases. With fixed transport, GC separation leads to its deviation out of the bay, which could weaken the cyclonic circulation inside the bay. Stronger intrusive GC and hence cyclonic circulation in the bay were intensified when nonlinear terms in momentum equation were dropped. It also deepened $h_{1}$, especiallynear the bay entrance. Similarly, increasing horizontal eddy viscosity $\left(K_{u}=60 \mathrm{~m}^{2} / \mathrm{s}\right)$ would decrease Reynolds number (and nonlinearity) of flow and its separation (Fig. 14) although the circulation strength was weakened too.

\section{Experiments with model parameters}

The parameters in the main run were chosen by comparing the model results and available observations (Gan et al., 1995a). In this section, the sensitivity of the model to changes of internal mixing parameters will be investigated. The control run was based on the parameters listed in Table 1. Individual sensitivity runs will be compared with the main run $\left(E_{1}\right)$. 

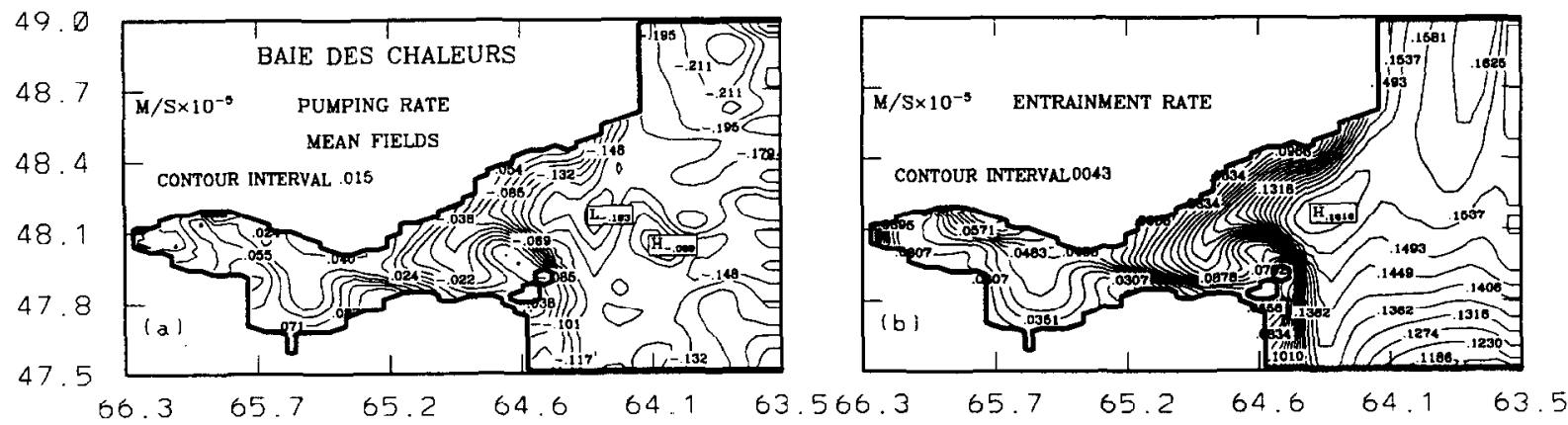

Fig. 12. a.b. Difference of two-month mean (a) pumping rate, $-\nabla\left(h_{1} \mathbf{V}_{1}\right)$ and (b) entrainment rate, $W_{e}$, between the cases with air temperature lowered $5^{\circ} \mathrm{C}$ and the main run.

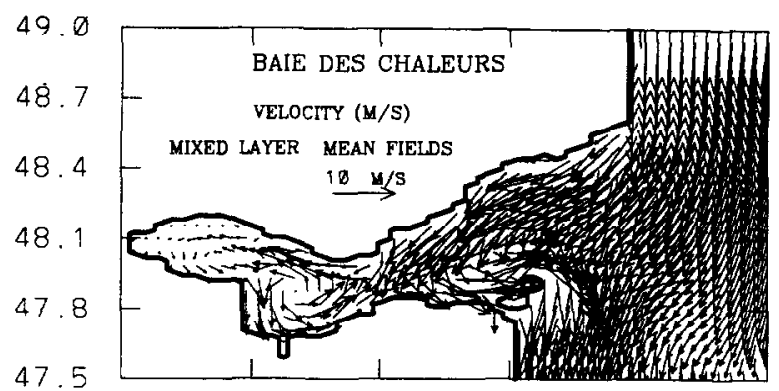

Fig. 13. Similar to Fig. 3, but without inclusion of nonlinear terms in momentum equations.

\subsection{Experiment $E_{2}\left(h_{s}=23 m, C_{r}=0.42\right)$}

These values of $h_{s}$ (attenuation depth of short wave radiation) and $C_{r}$ (percentage of penetrating short wave radiation) correspond to a clear type of water (Paulson and Simpson, 1977), while those in the main run are close to more turbid water. Similar to the finding of Martin (1985), it leads to a lower $\left|Q_{1}\right|$ and $T_{1}$, but increases $h_{1}$ (Fig. 15) since more incoming solar radiation is allowed to penetrate into the subsurface layer. $T_{2}$ also increased by $0.3^{\circ}$ in the bay. The $\mathrm{BdC}$ is a coastal bay where local discharge and shallow water make the water more turbid than in open ocean. Thus, more solar radiation was trapped in the layer near the surface than in clear water.

\subsection{Experiment $E_{3}\left(h_{d}=40 \mathrm{~m}\right)$}

A wide range of the $h_{d}$ (penetration depth of wind-driven turbulence) values have been applied

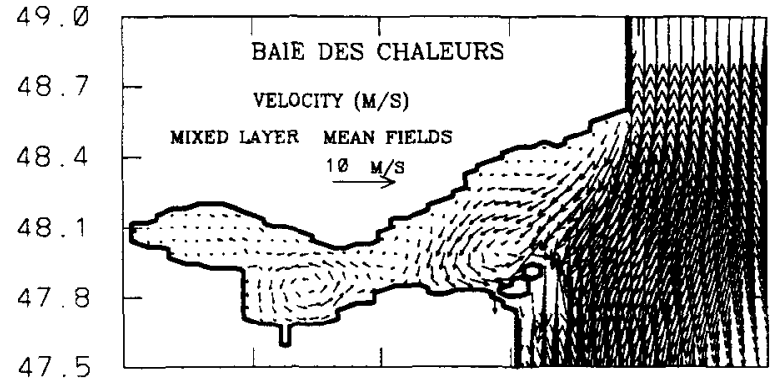

Fig. 14. Similar to Fig. 3, but with higher horizontal eddy viscosity.

in different ocean regions. Lemke (1987) used $h_{d}=7 \mathrm{~m}$ in the Arctic and Southern Ocean, while Cherniawsky et al. (1990) applied $h_{d}=30 \mathrm{~m}$ in their large scale modelling of the Atlantic Ocean. In Oberhuber's (1992) isopycnal GCM, this value was chosen as a latitude dependent function $k u_{*} / f(k=0.4$ and $f$ is Coriolis parameter $)$. Increasing $h_{d}$ deepens the penetration depth scale of wind-driven turbulent dissipation, which corresponds to an increase in the TKE from wind stress. This leads to a stronger entrainment, deeper $h_{1}$ but slightly lower $T_{1}$ (Fig. 15).

\subsection{Experiment $E_{4}\left(H N=5 \times 10^{-6} \mathrm{~m} / \mathrm{s}\right)$}

$H N$, the vertical eddy diffusive coefficient for deep diffusion in the model was $5 \times 10^{-7} \mathrm{~m} / \mathrm{s}$, which corresponds to a time scale of about 14 months for an $h_{2}$ of $20 \mathrm{~m}$. This time scale had little effect on the six month time scale of model integration. Increasing $H N$ to $5 \times 10^{-6} \mathrm{~m} / \mathrm{s}$ 


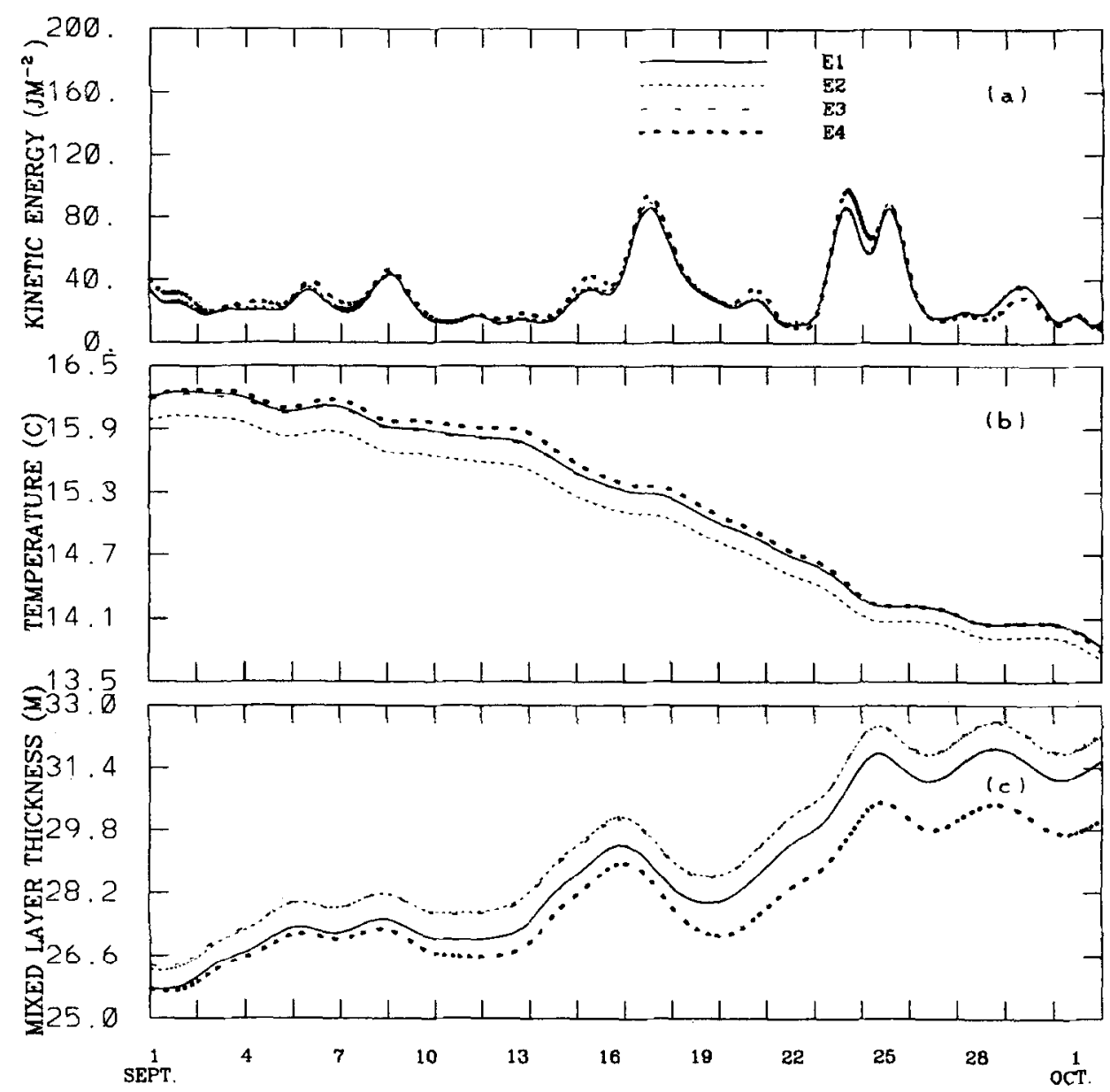

Fig. 15. Time series of bay-averaged $\mathrm{KE}_{1}$ temperature and thickness at $\mathrm{ML}$ for four different internal parameters. Experiment $\mathrm{E}_{2}$ refers to the case with $h_{s}$ and $C_{r}$ for clear water type, $E_{3}$ with higher penetration scale of wind-driven tusbulence and $E_{4}$ with stronger $H N$.

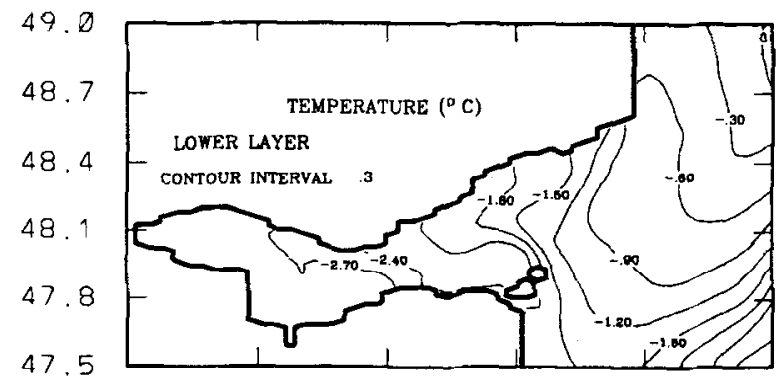

Fig. 16. Difference of two-month mean temperature in the subsurface layer between the cases with increased vertical eddy diffusivity and the main run. would decrease the time scale of deep diffusion to about 46 days. Its influence on temperature was small at the ML (Fig. 15), but decreased subsurface temperature $2.7^{\circ} \mathrm{C}$ at the center of the bay and about $1^{\circ} \mathrm{C}$ in the Gulf, respectively (Fig. 16). $h_{1}$ was deepened with the stronger reaction in colder season. Unlike other parameters, $H N$ effect is closely related to the time scale concerned.

\subsection{Experiment $E_{5}\left(m_{0}=3\right)$}

The magnitude of the wind mixing efficiency coefficient, $m_{0}$, in literature ranges from 0.6 
(Stigebrandt, 1985) to 5 (Yuen et al., 1992). Increasing $m_{0}$ had the same effect as increasing $h_{d}$. With $m_{0}$ increased from 1.2 to 3 , the mean SST slightly decreased and $h_{1}$ increased about 1-2 m (Fig. 17). In fact, the efficiency of increasing wind-driven turbulence in $\mathrm{BdC}$ was reduced since the stronger GC-induced convergence dramatically increased $h_{1}$.

\subsection{Experiment $E_{\sigma}\left(m_{1}=0.75\right.$ if $\left.B_{0}<0\right)$}

Since convection occurred mainly in the cooling season, lowering the convective mixing coeffi- cient, $m_{1}$, which is associated with the frictional energy dissipation of convective mixing, reduced the efficiency of the convectively generated turbulence in the ML, and hence entrainment and $h_{1}$ in the cooling season (after Sept. 8). (Fig. 17)

\subsection{Experiment $E_{7}$ (depth weighted average for $T_{e}$ and $S_{e}$ )}

In the model, the temperature and salinity at the transition layer $\left(T_{e}\right.$ and $\left.S_{e}\right)$ were calculated by using $T_{2}, T_{3}, S_{2}$ and $S_{3}$, and by assuming linear stratification in the subsurface layer. An-

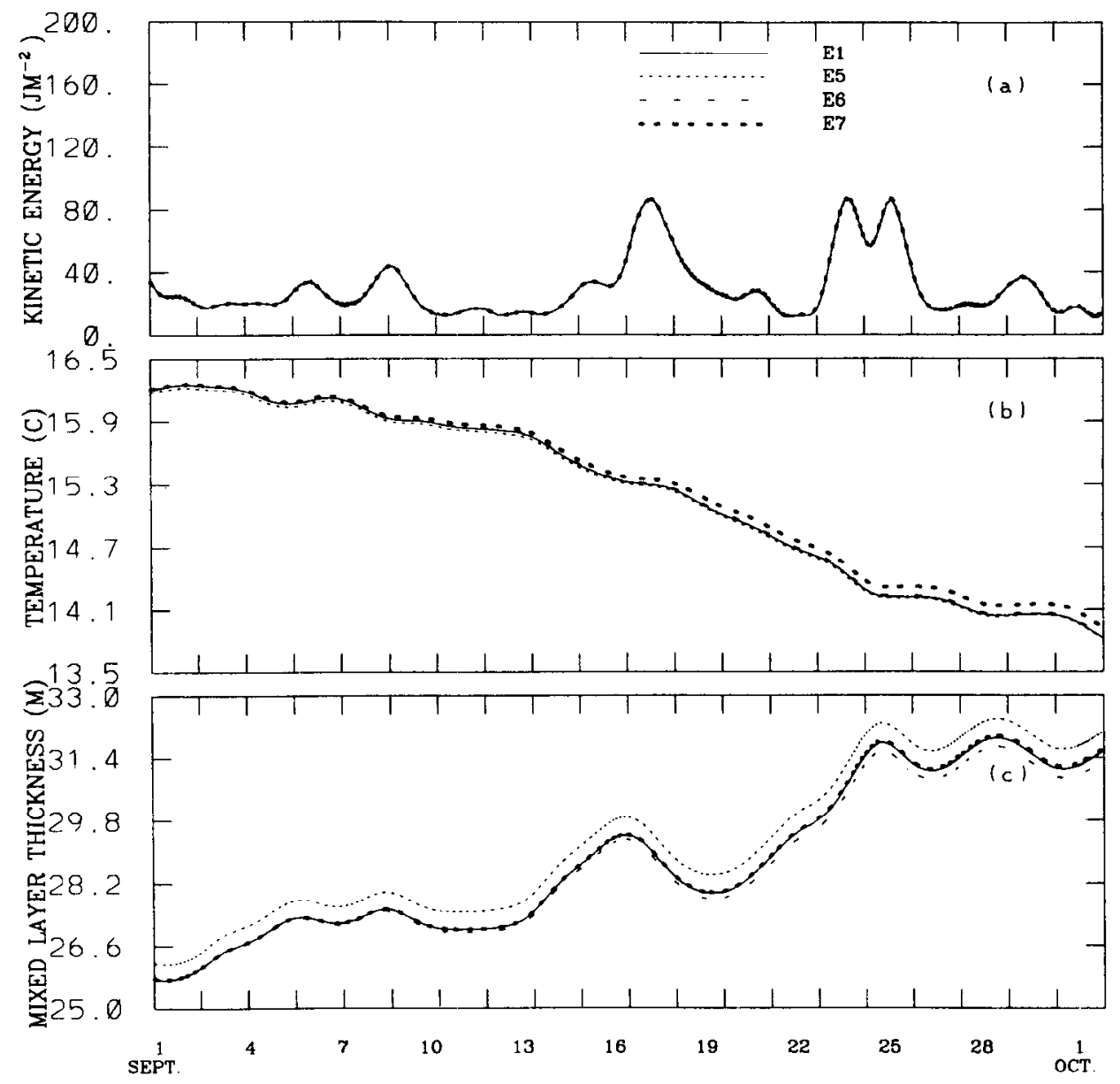

Fig. 17. Time series of bay-averaged KE, temperature and thickness at ML for four different internal parameters. Experiment $\mathrm{E}_{5}$ refers to the case with lower $m_{0}, \mathrm{E}_{6}$ with lower $m_{1}$ and $\mathrm{E}_{7}$ with depth weighted interfacial temperature and salinity. Fig. 17a, b. Difference of two-month mean (a) mixed layer depth and (b) SST between the cases with $R i_{\text {crit. }}=0$ and the main run. 

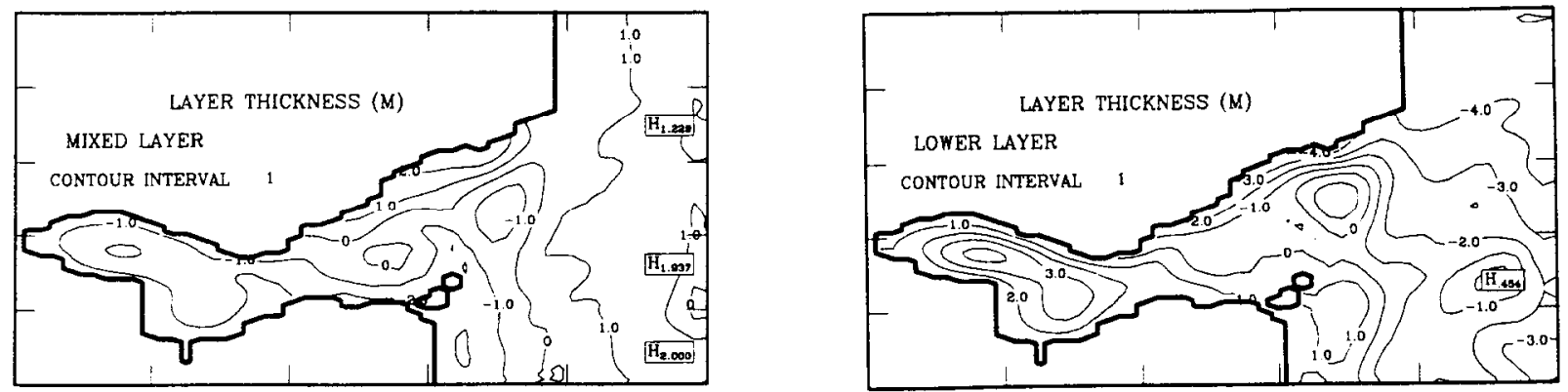

Fig. 18. Difference of two-month mean of (right) subsurface layer depth and (left) mixed layer depth between the cases with decreased $H_{e}$ and the main run.

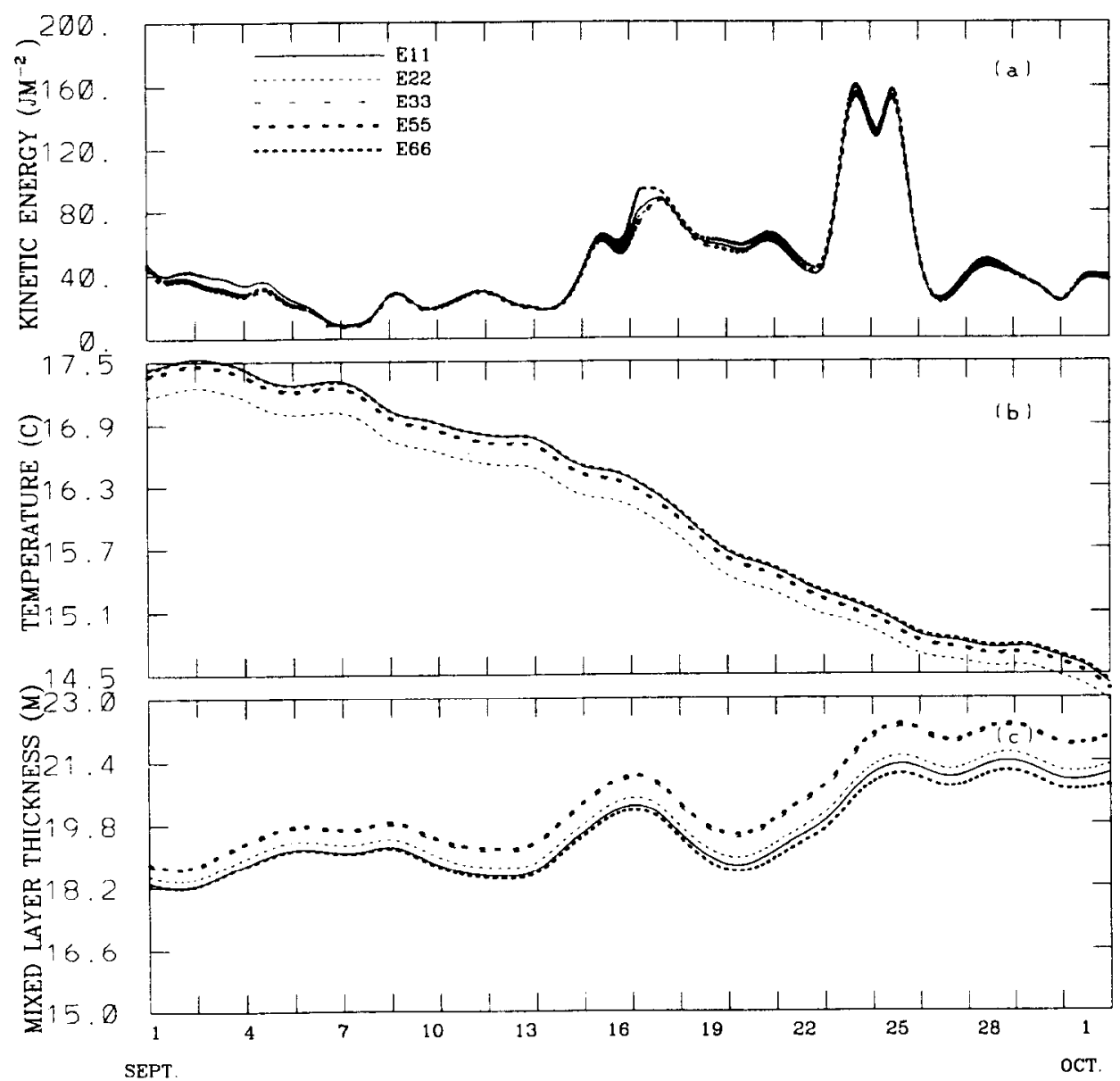

Fig. 19. Similar to both Fig. 15 and Fig. 17. The experiment number was repeated, indicating that the GC was not included in these runs. 
other approach was tested, by using $(T, S)_{e}=(1$ $-e)\left(T_{1}, S_{1}\right)+e\left(T_{2}, S_{2}\right)$ and $e=e_{0} h_{2} /\left(h_{1}+h_{2}\right)$, where $e_{0}=0.5$. This parameterisation has been used by Lemke (1987), Cherniawsky et al. (1990) and Yuen et al. (1992). The difference of the $T_{e}$ from linear stratification assumption and depth weighted scheme is $\Delta T_{e}=\left(T_{2}-T_{1}\right)\left(4 h_{1}+\right.$ $\left.3 h_{2}\right) /\left(h_{1}+h_{2}\right)$. In the cold season, strong surface cooling dramatically lowered $T_{1}$ and deepened $h_{1}$. Thus, a larger difference between these two schemes occurred in cold season. Results using this parameterisation show that it leads to higher $T_{e}$ in the cold season. $T_{1}$ increased by about $0.1-0.2^{\circ} \mathrm{C}$ with a slightly change of $h_{1}$ in the cold season (Fig. 17). Indeed, a slight increase in the depth weighted constant $e_{0}$ would lead to no difference between two schemes. Cherniawsky and Holloway (1991) also examined sensitivity to parameterisations of $(T, S)_{e}$ by using an improved version of the model of Cherniawsky et al. (1990).

\subsection{Experiment $H_{e}=15 \mathrm{~m}$}

Decreasing $H_{e}$ by $5 \mathrm{~m}$ in August and September resulted in $h_{2}$ being less constrained. It then allowed $h_{2}$ to reach a shallower depth in the Gulf region, where the stronger convergence induced by the GC caused ML deepening. Since $h_{2}$ at the west of the bay was generally greater than $H_{e}, W_{\mathrm{r}}$ was generated there in the requirement of mass conservation due to $W_{\mathrm{r}}>0$ in the Gulf and at the entrance of the bay. With prescribed $H_{e}$ decreased, it also decreased $\left|W_{\mathrm{r}}\right|$ at the west of the bay and hence deepened $h_{2}$ there. However, change in $H_{e}$ had little effect on the $\mathrm{ML}$ in the bay (Fig. 18b). The experiment with $W_{\mathrm{r}}$ equal to zero had a similar effect as those found in this subsection.

\subsection{Experiment without Gaspé Current}

This experiment not only tests the external forcing effects on BdC but also illustrates the sensitivity of parameters in the entrainment calculation to a different forcing system. Without the GC, the prevailing westerlies dominated. Although the corresponding stronger upwelling can raise more cold water to the ML by increasing entrainment, the exclusion of stronger cold water advection by the GC dramatically raised mean SST in the bay (Fig. 19). Without GC induced convergence and with westerlies induced upwelling, mean MLD shoaled almost $10 \mathrm{~m}$. The sensitivity of model solutions to parameter changes in the entrainment formula is somewhat different from those when the GC was not included (Fig. 19). $h_{1}$ is less sensitive to changes of $h_{\mathrm{s}}\left(\mathrm{F}_{22}\right)$, but $T_{1}$ is about the same as compares to $\mathrm{E}_{2}$. Sensitivity to $h_{\mathrm{d}}\left(\mathrm{E}_{33}\right)$ is also about the same as the case with $\mathrm{GC}\left(\mathrm{E}_{3}\right)$. However, the solutions were more sensitive to $m_{0}$ when the GC was not included $\left(\mathrm{E}_{55}\right.$ vs. $\left.\mathrm{E}_{5}\right)$. It also increased convective sensitivity in warm and decreased incooling season.

\section{Summary and conclusions}

The model consists of primitive equation dynamics combined with a mixed layer model, similar to Niiler and Kraus (1977). Mean kinetic energy from vertical shear instability was included in the entrainment/detrainment calculation.

The model was forced by hourly observed atmospheric data. The solutions were obtained at eddy-permitting resolution. It reproduced observed fields quite well.

To determine the importance of dynamical and thermodynamic external forcing, we performed experiments with stronger wind speed and a cooler atmosphere. In the first experiment, the mean cyclonic eddy at the central of the bay changed to anticyclonic. Although the circulation inside $\mathrm{BdC}$ was determined by both eastward prevailing winds and westward GC intrusion, the conditions near the entrance of the bay depended mainly on GC separation characteristics. Experiments with changing external thermal forcing not only changed the thermal field, but also modified dynamical processes. The results revealed that the fluctuations in SST were mainly due to latent and sensible heat change, which were correlated with both wind magnitude and air temperature.

To illustrate the importance of nonlinearity for the GC separation, we run the experiments by 
either dropping the nonlinear terms in momentum equations or increasing the horizontal eddy viscosity. Results indicated that the nonlinearity was very important in determining the coastal jet separation. It, thus, affected the conditions inside the bay. Increasing horizontal eddy viscosity would reduce the effects of the nonlinear terms in the momentum equation and weakened separation.

The good agreement between model solutions and observations suggests that the parameters applied in the $\mathrm{BdC}$ modelling were appropriate. The study also suggests that sensitivity of the ML physical parameters also depends on the dynamical and thermodynamic system applied. Some parameters which is not sensitive in one system may become important in another one.

\section{Acknowledgements}

Thanks to Drs. P. Chen and T. Warn for helpful discussions. Data was collected and processed by P. Peltola, Claude Belanger, M. EISabh, T. Vander Baaren, C. Le Quere and J.C. Croteau. Field work was jointly supervised by El-Sabh, RGI and other members of the OPEN Centre of Excellence. This work was supported by and is a contribution to the program of the Groupe Interuniversitaire de Recherche Oceanographiques du Quebec and OPEN (National Center of Excellence in Canada). Funds were also obtained from the Natural Science and Engineering Research Council of Canada (R.G.I. and R.J.G.) and the Fonds FCAR (R.G.I.).

\section{References}

Asselin, R., 1972. Frequency filters for time integrations. Mon. Weather Rev., 100: 487-490.

Benoit, J. and El-Sabh, M.I., 1985. Structure and seasonal characteristics of the Gaspe current. J. Geophys. Res. 90(C2): 3225-3236.

Batchelor, G.K., 1967. An Introduction to Fluid Dynamics. Cambridge University Press, 615 pp.

Bolton, D., 1980. The computation of equivalent potential temperature. Mon. Weather Rev., 108: 1046-1053.

Budyko, M.I., 1974. Climate and Life. Academic Press, New York, 66 pp.
Bugden, G.L., 1981. Salt and heat budgets for the Gulf of St, Lawrence. Can. J. Fish. Aquat. Sci., 38: 1153-1167.

Camerlengo, A.L. and O'Brien, J.J., 1980. Open boundary conditions in rotating fluids. J. Comput. Phys., 35: 12-35.

Cherniawsky, J.Y. and LeBlond, P.H., 1986. Rotating flows along indented coastlines. J. Fluid Mech., 169: 379-407.

Cherniawsky, J.Y., Yuen, C.W., Lin, C.A. and Mysak, L.A., 1990. Numerical experiments with a wind- and buoyancydriven two-and a half layer upper ocean model. J. Geophys. Res., 95(C9): 16,149-16,167.

Cherniawsky, J.Y. and Holloway, G., 1991. An upper ocean general circulation model for the North Pacific. Atmos. Ocean, 29: 737-784.

Dengg, J., 1993. The problem of Gulf Stream separation: A barotropic approach. J. Phys. Oceanogr., 23: 2183-2199

Denman, K.L., 1973. A time-dependent model of the upper ocean. J. Phys. Oceanogr., 13: 173-184.

El-Sabh, M.I., 1976. Surface circulation patterns in the Gulf of St. Lawrence, J. Fish. Res. Board Can., 33: 124-138.

Gan, J.P., Ingram, R.G., Greatbatch, R.J. and Chen, P., 1995a. Upper ocean modelling in a coastal bay. J. Geophys. Res. (in press).

Gan, J.P., Ingram, R.G. and Greatbatch, R.J., 1995b. On the separation/intrusion of Gaspe current and variability in Baie des Chaleurs, Part II: Modelling. submitted.

Garwood, R.W., Jr., 1977. An oceanic mixed-layer model capable of simulating cyclic states. J. Phys. Oceanogr., 7: 455-471.

Greatbatch, R.J. and Otterson, T., 1991. On the formulation of open boundary conditions at the mouth of a bay. $J$. Geophys. Res., 96(C10): 18,431-18,445.

Hsu, S.A., 1986. Correction of land-based wind data for offshore applications: A further evaluation. J. Phys. Oceanogr., 16: 390-394.

Kim, J.-W., 1976. A generalized bulk model of the ocean mixed layer. J. Phys. Oceanogr., 6: 686-695.

Kraus, E.B. and Turner, J.S., 1967. A one-dimensional model of seasonal thermocline. II: The general theory and its consequences. Tellus, 19: 98-109.

Large, W.G. and Pond, S., 1980. Open ocean momentum flux measurements in moderate to strong winds. J. Geophys. Res., 11: 324-336.

Lemkc, P., 1987. A coupled one-dimensional sea ice-ocean model. J. Geophys. Res., 92(C12): 13,164-13,172.

Martin, P.J., 1985. Simulation of the mixed layer at OWS November and Papa with several models. J. Geophys. Res., 90(C1): 903-916.

McCreary, J.P. and Kundu, P., 1988. A numerical investigation of the Somali Current during the Southwest Monsoon. J. Mar. Res., 46: 25-58.

Mertz, G., El-Sabh, M.I. and Denis, P., 1988. Instability of a buoyancy-driven coastal jet: the Gaspe current and its $\mathrm{St}$. Lawrence precursor. J. Geophys. Res., 93(C6): 6885-6893.

Niiler, P.P. and Kraus, E.B., 1977. One-dimensional models of the upper ocean. In: E.B. Kraus (Editor), Modelling and Prediction of the Upper Layers of the Ocean. Pergamon, New York, pp. 143-172. 
Oberhuber, J.M., 1992. Simulation of the Atlantic circulation with a coupled sea ice-mixed layer-isopycnal general circulation model. Part I: Model description. J. Phys. Oceanogr., 23: 808-828.

Paulson, C.A. and Simpson, J.J., 1977. Irradiance measurements in the upper ocean. J. Phys. Oceanogr., 7: 952-956.

Petrie, B., 1990. Monthly Means of Temperature, Salinity and Sigma-t for the Gulf of St. Lawrence. Can. Tech. Rep. Hydrogr. Ocean Sci., 126.

Schopf, P.S. and Cane, M., 1983. On the equatorial dynamics, mixed layer physics and sea surface temperature. J. Phys. Oceanogr., 13: 917-935.

Stigebrandt, A., 1985. A model for seasonal pycnocline in rotating systems with application to the Baltic proper. J. Phys. Oceanogr. 15: 1392-1404.

Yuen, C.W., Cherniawsky, J.Y., Lin, C.A. and Mysak, L.A., 1992. An upper ocean general circulation model for climate studies: global simulation with seasonal cycle. Clim. Dyn., 7: 1-18. 